\title{
Determination of myrislignan levels in BALB/c mouse plasma by LC-MS/MS and a comparison of its pharmacokinetics after oral and intraperitoneal administration
}

\author{
Jili Zhang ${ }^{1,2,3}$, Hongfei $\mathrm{Si}^{4}$, Jichao Sun ${ }^{5}$, Kun Lv ${ }^{6}$, Biqing Yan ${ }^{1}$, Bing $\mathrm{Li}^{3}$, Xuzheng Zhou ${ }^{3}$ and Jiyu Zhang ${ }^{3,7^{*}}$
}

\begin{abstract}
Background: Myrislignan is a natural product from Myristica sp. with diverse pharmacological activities. Recently, the anti-Toxoplasma gondii (T. gondii) activity of myrislignan has been proposed, and in vivo studies of its pharmacokinetics in BALB/C mice are necessary to further evaluate the clinical effects of myrislignan.

Results: In this study, a sensitive liquid chromatography-tandem mass spectrometry (LC-MS/MS) method was developed and validated to quantify myrislignan levels in mouse plasma using dehydrodiisoeugenol as an internal standard (IS) in positive ion mode. Chromatographic separation of the analytes was achieved using an ACE Ultracore Super C18 analytical column $(2.5 \mu \mathrm{m}, 2.1 \times 50 \mathrm{~mm})$ at $30^{\circ} \mathrm{C}$. A gradient mobile phase consisting of water ( $0.1 \%$ formic acid) and acetonitrile ( $0.1 \%$ formic acid) was delivered at a flow rate of $0.4 \mathrm{~mL} / \mathrm{min}$. Myrislignan and the IS eluted at 1.42 and 1.71 min, respectively. A good excellent linear response across the concentration range of $1-1000 \mathrm{ng} / \mathrm{mL}$ was achieved $\left(r^{2}=0.9973\right)$. The lower limit of quantification (LLOQ) was $1 \mathrm{ng} / \mathrm{mL}$, and the inter- and intra-day accuracy and precision of the method showed relative standard deviations (RSDs) less than $10 \%$. The method was applied to examine the pharmacokinetics of myrislignan in mouse plasma following a single oral administration of $200 \mathrm{mg} / \mathrm{kg}$ or intraperitoneal administration of $50 \mathrm{mg} / \mathrm{kg}$ myrislignan, and the bioavailability (F) of orally administered myrislignan was only $1.97 \%$ of the bioavailability of intraperitoneally administered myrislignan.

Conclusions: A rapid and sensitive LC-MS/MS method has been was developed, validated and successfully used to determine myrislignan levels in mice after oral or intraperitoneal administration. This study is the first to report the pharmacokinetic parameters of myrislignan in mice and to compare its pharmacokinetics after oral and intraperitoneal administration, which will be useful for further research on the administration of myrislignan in animals and humans.
\end{abstract}

Keywords: Myrislignan, Pharmacokinetics, LC-MS/MS, Mouse, Dehydrodiisoeugenol, Bioavailability

\footnotetext{
* Correspondence: zhangjiyu@caas.cn

${ }^{3}$ Lanzhou Institute of Husbandry and Pharmaceutical Sciences, Chinese Academy of Agricultural Sciences, Gansu Province, Lanzhou, People's Republic of China

${ }^{7}$ Key Laboratory of Veterinary Pharmaceutical Development, Lanzhou Institute of Husbandry and Pharmaceutical Sciences, Chinese Academy of Agricultural Sciences, 730050 Lanzhou, People's Republic of China Full list of author information is available at the end of the article
}

(c) The Author(s). 2021 Open Access This article is licensed under a Creative Commons Attribution 4.0 International License, which permits use, sharing, adaptation, distribution and reproduction in any medium or format, as long as you give appropriate credit to the original author(s) and the source, provide a link to the Creative Commons licence, and indicate if changes were made. The images or other third party material in this article are included in the article's Creative Commons licence, unless indicated otherwise in a credit line to the material. If material is not included in the article's Creative Commons licence and your intended use is not permitted by statutory regulation or exceeds the permitted use, you will need to obtain permission directly from the copyright holder. To view a copy of this licence, visit http://creativecommons.org/licenses/by/4.0/. The Creative Commons Public Domain Dedication waiver (http://creativecommons.org/publicdomain/zero/1.0/) applies to the data made available in this article, unless otherwise stated in a credit line to the data. 


\section{Background}

Myristica fragrans Houtt (Myristicaceae) is an aromatic evergreen tree formerly known as a spice [1]. Its seeds, nutmeg, are used not only for cooking but also for medicinal purposes since they have a wide range of pharmacological activities, including anti-inflammatory [2], antibacterial [3], antiangiogenic [4], anticarcinogenic [5], antidiarrhoeal [6] and antiplatelet aggregation [7] activities. Myrislignan is the main active ingredient (greater than $3.5 \mathrm{mg} / \mathrm{g}$ crude drug) in nutmeg and was discovered in 1973 [8]. Myrislignan possesses various biological activities since it significantly inhibits nitric oxide production [9]; affects hepatic mixed function oxidase enzyme activity [10]; protects against thioacetamideinduced liver injury [11]; exerts anti-inflammatory [12], antifeeding [8], anticancer [13], and antifungal effects [14]; and inhibits neoplasm formation and vascular smooth muscle contraction $[15,16]$. In addition, myrislignan is readily transported in the Caco- 2 cell monolayer model [17] and penetrates the blood-brain barrier through passive diffusion [18]. Thus, myrislignan appears to be a promising drug candidate for further pharmaceutical development.

Recently, we identified the anti-Toxoplasma activity of myrislignan; thus, in vivo studies of its pharmacokinetics are necessary to evaluate the clinical effects of myrislignan. To date, only a few methods for the determination of myrislignan have been reported. One of the pharmacokinetic studies of myrislignan in rats after intravenous administration used high-performance liquid chromatography (HPLC), and the lower limit of quantification (LLOQ) was only $300 \mathrm{ng} / \mathrm{mL}$ [19]. In another study, an ultra-high ultrahigh-performance liquid chromatography coupled with mass spectrometry (UPLC-MS) method was developed for the determination of myrislignan levels in rat plasma after oral administration [20]. However, no information about the pharmacokinetics of myrislignan in mice after dosing has been reported. In this study, a simple and sensitive liquid chromatography-tandem mass spectrometry (LCMS/MS) method was developed for the determination of myrislignan levels in mouse plasma after oral and intraperitoneal administration. The method was successfully used for a comparative pharmacokinetic study of myrislignan after oral administration and intraperitoneal injection in mice, and the bioavailability of myrislignan in mice was calculated.

\section{Results}

Mass spectrometry and liquid chromatography

To optimize the mass spectrometric parameters of myrislignan and the IS, electrospray ionization (ESI) full scans were performed in both ESI $( \pm)$ detection modes.
Better MS responses were achieved in the ESI $(+)$ mode compared with than in the ESI (-) mode. The scanning MS spectra demonstrated $[\mathrm{M}+\mathrm{Na}]^{+}$ions at $\mathrm{m} / \mathrm{z} 397.4$ for myrislignan and $[\mathrm{M}+\mathrm{H}]^{+}$ions at $\mathrm{m} / \mathrm{z} 327.4$ for the IS (Fig. 1). Analyte quantification was performed using the multiple reaction monitoring (MRM) mode to acquire data with high selectivity and sensitivity. In MRM mode, the mass transitions chosen for quantitation were $\mathrm{m} / \mathrm{z} 397.4$ to 216.1 for myrislignan and $\mathrm{m} / \mathrm{z} 327.4$ to 203.3 for the IS.

Chromatographic separations were conducted on an ACE Ultracore Super C18 analytical column $(2.5 \mu \mathrm{m}$, $2.1 \times 50 \mathrm{~mm}$ ) at a flow rate of $0.4 \mathrm{~mL} / \mathrm{min}$. The analysis was conducted with gradient elution using mobile phase A, $0.1 \%$ formic acid (FA) in water, and mobile phase B, $0.1 \% \mathrm{FA}$ in acetonitrile (ACN). Under this these conditions, myrislignan and the IS were well resolved with retention times of 1.42 and $1.71 \mathrm{~min}$, respectively, and endogenous substances in the plasma did not interfere with analyte detection.

\section{Method validation \\ Selectivity and matrix effects}

Specificity assays were assessed by analysing blank plasma samples from nine different mice under the above chromatographic conditions. Figure 2 shows representative chromatograms of blank plasma, a real plasma sample collected after oral administration, and a plasma sample at the LLOQ $(1 \mathrm{ng} / \mathrm{mL})$. The assay was free of interference from endogenous substancemediated interference near the retention times of for myrislignan or the IS.

In addition, the mean matrix effect for myrislignan was $91.61 \pm 3.63 \%$, while the matrix effect on the IS was $90.10 \pm 2.37 \%$. The results indicated that there was no significant interference in this assay from the plasma matrix.

\section{LLOQ and linearity}

The LLOQ and lower limit of detection (LLOD) of myrislignan were $1 \mathrm{ng} / \mathrm{mL}$ and $0.5 \mathrm{ng} / \mathrm{mL}$, respectively. Furthermore, the calibration curves are were established within the concentration range of $1-1000 \mathrm{ng} / \mathrm{mL}$, as shown in Fig. 3. The typical equation of the calibration curve for myrislignan was $\mathrm{y}=0.00202 \mathrm{x}-0.00104\left(r^{2}=\right.$ 0.9973 ) with a weighting factor of $1 / x^{2}$, exhibiting an good excellent linearity across the entire calibration range.

\section{Accuracy and precision}

The intra- and inter-day precision and accuracy based on the quality control (QC) samples $(15 \mathrm{ng} / \mathrm{mL}, 400 \mathrm{ng} /$ $\mathrm{mL}$ and $800 \mathrm{ng} / \mathrm{mL})$ and LLOQ samples $(1 \mathrm{ng} / \mathrm{mL})$ are summarized in Table 1 . The intraday accuracy for 

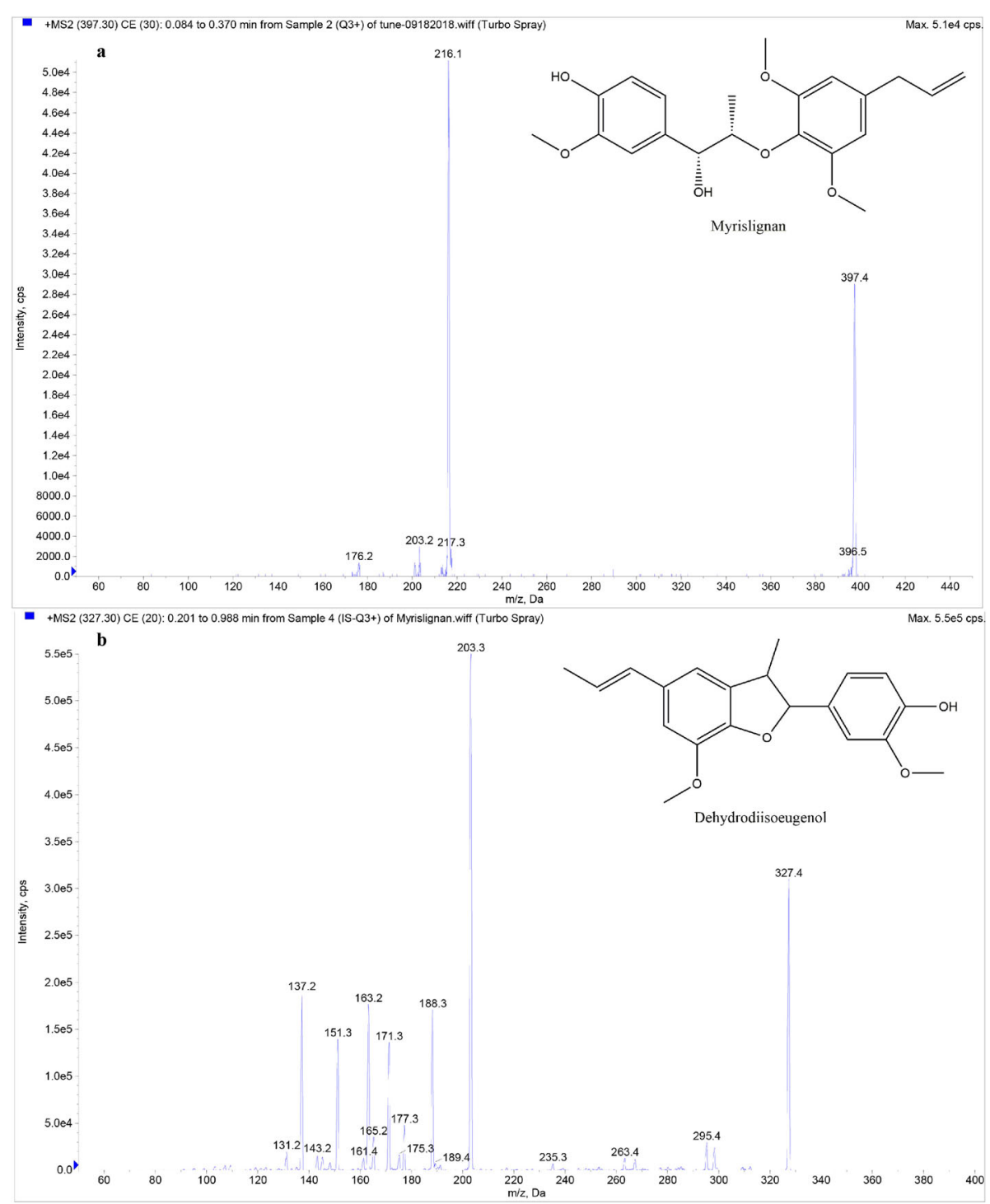

Fig. 1 Full-scan product ion spectra of myrislignan (a) and dehydrodiisoeugenol (b)

myrislignan ranged from 97.11 to $111.60 \%$, and the interday accuracy ranged from 99.63 to $109.81 \%$. The intra- and inter-day precisions were $3.73-7.51 \%$ and $2.72-6.34 \%$, respectively. The results showed that this method was accurate, reliable and reproducible.

\section{Recovery}

The mean extraction recoveries of myrislignan at concentrations of $15.0 \mathrm{ng} / \mathrm{mL}, 400 \mathrm{ng} / \mathrm{mL}$ and $800 \mathrm{ng} / \mathrm{mL}$ were $101.83 \pm 9.72 \%, \quad 101.50 \pm 3.06 \%$, and $109.33 \pm$ $6.79 \%$, respectively. The mean extraction recovery for IS was $103.76 \pm 1.89 \%$. The results are shown in Table 2, which was demonstrated demonstrating that the extraction method was simple and efficient.

\section{Stability}

The stabilities of myrislignan under different storage conditions are shown in Table 3. The accuracy was 92.22-110.02\%, and the precision (RSD\%) was 1.83$7.70 \%$, indicating that myrislignan was fairly stable under all of the tested conditions.

\section{Dilution integrity}

The plasma concentration of myrislignan after intraperitoneal administration exceeded the linear range. Therefore, the dilution effect on myrislignan was studied. The precision and accuracy of 10 -fold diluted plasma samples $(n=6)$ were 6.9 and $106.83 \%$, respectively. 

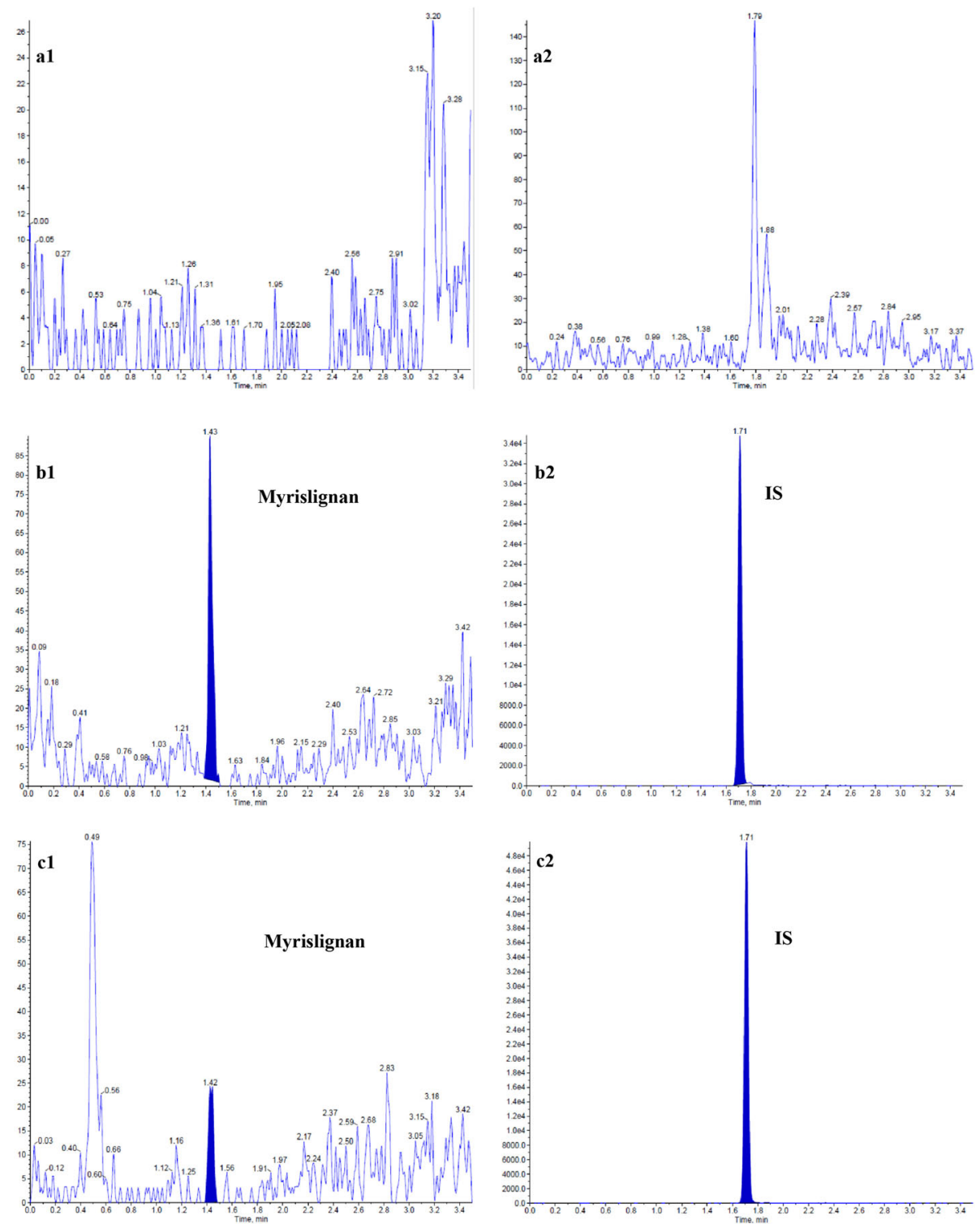

Fig. 2 Representative chromatograms of myrislignan and the IS in plasma. a blank plasma; b a plasma sample obtained after oral administration of $200 \mathrm{mg} / \mathrm{kg}$ of myrislignan; c a blank plasma sample spiked with the LLOQ

\section{Pharmacokinetic studies}

The plasma concentrations of myrislignan were quantitated after oral or intraperitoneal administration at doses of $200 \mathrm{mg} / \mathrm{kg}$ or $50 \mathrm{mg} / \mathrm{kg}$, respectively. The mean plasma concentration-time profiles of myrislignan are shown in Fig. 4. In addition, the major pharmacokinetic parameters of myrislignan after oral or intraperitoneal administration were determined using a noncompartment model and are listed in Table 4. After oral administration of $200 \mathrm{mg} / \mathrm{kg}$ myrislignan, the compound reached a half-life After oral administration of $200 \mathrm{mg} /$ $\mathrm{kg}$ myrislignan, the compound was absorbed and reached a half-life $\left(\mathrm{T}_{1 / 2}\right)$ of $1.97 \pm 0.426 \mathrm{~h}$, peak plasma concentration $\left(\mathrm{C}_{\max }\right)$ of $105 \pm 72.3 \mathrm{ng} / \mathrm{mL}$, peak time
$\left(\mathrm{T}_{\max }\right)$ of $1.04 \pm 1.45 \mathrm{~h}$, and average area under the curve $\left(\mathrm{AUC}_{0-\mathrm{t}}\right)$ of $157 \pm 55.1 \mathrm{~h} / \mathrm{ng} / \mathrm{mL}$. The $\mathrm{C}_{\max }$ of myrislignan in mice following intraperitoneal administration was $3870 \pm 1200 \mathrm{ng} / \mathrm{mL}$, the $\mathrm{AUC}_{0-\mathrm{t}}$ of myrislignan in the intraperitoneal group was $2050 \pm 532 \mathrm{~h} / \mathrm{ng} / \mathrm{mL}$, the $\mathrm{T}_{1 / 2}$ was $0.692 \pm 0.386 \mathrm{~h}$, and the $\mathrm{T}_{\max }$ was $0.167 \pm$ $0.0915 \mathrm{~h}$. The bioavailability (F) of orally administered myrislignan was only $1.97 \%$ compared with that of the intraperitoneal group.

\section{Discussion}

In the method development stage, because the detection limit of HPLC is too high to accurately evaluate the pharmacokinetics level of myrislignan in mice, the LC- 


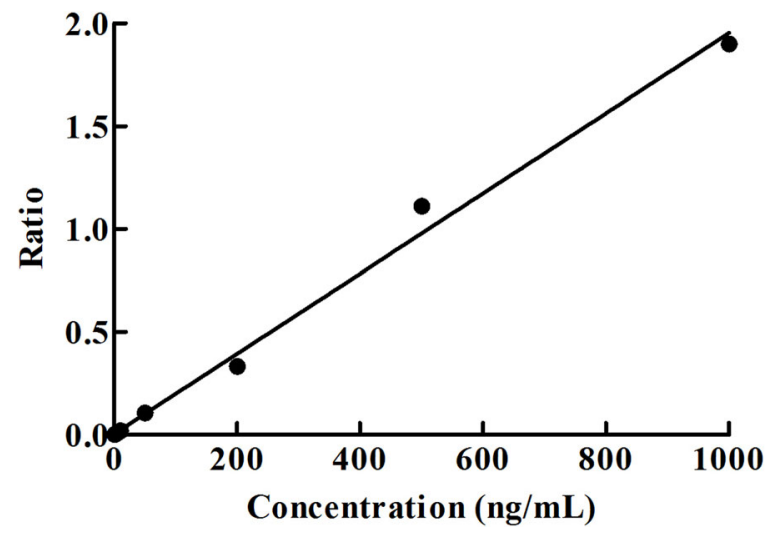

Fig. 3 The calibration curves

MS/MS method was used to meet the experimental requirements. Under the optimal LC conditions, FA was added to increase the ionization of all of the tested compounds and to improve the peak shape. The composition of the mobile phase in this study was deemed suitable for the separation and ionization of myrislignan and the IS, as since it provided a good peak shape and resolution. In addition, procedures used to validate the optimized bioanalytical method for myrislignan were performed in accordance with FDA guidelines [21]. The LC-MS/MS method was validated in terms of selectivity, linearity, matrix effect, LLOQ, recovery, accuracy and precision, stability and dilution integrity. Here, a good well linear relationship between the ratio of the myrislignan concentration and the quantitative ion peak area was established. The method displayed satisfactory accuracy, precision and reproducibility for the quantification of myrislignan levels in mouse plasma, and no endogenous substance-mediated interference was observed. Liquid-liquid extraction with acetonitrile was both simple and efficient, and the plasma samples containing concentrations greater than the maximum value of the calibration curve were also accurately measured. In addition, myrislignan was stable in mouse plasma after exposure to different storage conditions. Thus, the LC-MS/MS method developed and validated in our study was simple and sensitive.

Table 1 Intra- and inter-day precision and accuracy of the determination of myrislignan in mouse plasma

\begin{tabular}{|c|c|c|c|c|}
\hline \multirow[t]{2}{*}{$\begin{array}{l}\text { Concentration } \\
(\mathrm{ng} / \mathrm{mL})\end{array}$} & \multicolumn{2}{|c|}{$\begin{array}{l}\text { Intra-day precision and } \\
\text { accuracy }(n=6)\end{array}$} & \multicolumn{2}{|c|}{$\begin{array}{l}\text { Inter-day precision and } \\
\text { accuracy }(n=18)\end{array}$} \\
\hline & $\begin{array}{l}\text { Accuracy }(\%) \pm \\
\text { SD }\end{array}$ & $\begin{array}{l}\text { RSD } \\
\text { (\%) }\end{array}$ & $\begin{array}{l}\text { Accuracy }(\%) \pm \\
\text { SD }\end{array}$ & $\begin{array}{l}\text { RSD } \\
(\%)\end{array}$ \\
\hline 1 & $111.60 \pm 7.76$ & 6.96 & $109.81 \pm 4.56$ & 4.15 \\
\hline 15 & $97.11 \pm 7.30$ & 7.51 & $103.57 \pm 6.57$ & 6.34 \\
\hline 400 & $108.08 \pm 4.02$ & 3.73 & $99.63 \pm 3.04$ & 3.05 \\
\hline 800 & $108.92 \pm 5.54$ & 5.08 & $101.32 \pm 2.76$ & 2.72 \\
\hline
\end{tabular}

Table 2 Recovery of myrislignan $(n=6)$ from mouse plasma

\begin{tabular}{llll}
\hline \multicolumn{2}{l}{ Concentration $(\mathbf{n g} / \mathbf{m L})$} & \multicolumn{2}{l}{ Recovery $(\%, \boldsymbol{n}=\mathbf{6})$} \\
\cline { 3 - 4 } & & Mean $(\%) \pm$ SD & RSD (\%) \\
\hline Myrislignan & 15 & $101.83 \pm 9.72$ & 9.55 \\
& 400 & $101.50 \pm 3.06$ & 3.01 \\
& 800 & $109.33 \pm 6.79$ & 6.21 \\
IS & & $103.76 \pm 1.89$ & 1.82 \\
\hline
\end{tabular}

The pharmacokinetic parameters of myrislignan in mouse plasma were successfully obtained in this study. Based on previously published data obtained after the oral administration of $18.3 \mathrm{mg} / \mathrm{kg}$ myrislignan [22], the $\mathrm{C}_{\max }$ and $\mathrm{AUC}_{0-\mathrm{t}}$ in rats are were $102.44 \pm 16.51 \mathrm{ng} / \mathrm{mL}$ and $158.09 \pm 40.40 \mathrm{~h} / \mathrm{ng} / \mathrm{mL}$, respectively, while the pharmacokinetic properties obtained for myrislignan after oral administration at a dose of $200 \mathrm{mg} / \mathrm{kg}$ in mice were $C_{\max }$ and $\mathrm{AUC}_{0-\mathrm{t}}$ values of $105 \pm 72.3 \mathrm{ng} / \mathrm{mL}$ and $157 \pm 55.1 \mathrm{~h} / \mathrm{ng} / \mathrm{mL}$, respectively. The results obtained after oral administration in mice were all lower than those obtained after intraperitoneal administration (50 mg/kg), showing $C_{\max }$ of $3870 \pm 1200 \mathrm{ng} / \mathrm{mL}$ and $\mathrm{AUC}_{0-\mathrm{t}}$ of $2050 \pm 532 \mathrm{~h} / \mathrm{ng} / \mathrm{mL}$. These results indicated that the oral absorption of myrislignan was limited. However, a higher $\mathrm{MRT}_{0-t}$ value was observed in the oral administration group than in the intraperitoneal group. These results highlight emphasize that the pharmacokinetics of myrislignan in mice were characterized by rapid absorption and metabolism, as well as poor oral absorption since its oral bioavailability was only $1.97 \%$, and they suggest that intraperitoneal injection could achieve a higher blood concentration. Recently, we observed the anti- $T$. gondii activity of myrislignan. The pharmacokinetic data presented in the present study could provide a basis for further clinical studies of the pharmacodynamics of myrislignan.

\section{Conclusions}

A rapid and sensitive LC-MS/MS method has been developed, validated and successfully used to determine myrislignan levels in mice after oral or intraperitoneal administration. The sample preparation procedure for the assay is simple and relatively quick, and the analysis method provides excellent sensitivity, linearity, precision and accuracy. This method was successfully used in the pharmacokinetic evaluation of myrislignan in mice after oral or intraperitoneal administration. This study is the first to report the pharmacokinetic parameters of myrislignan in mice and to compare its pharmacokinetics after oral and intraperitoneal administration, which could be useful for further research on the administration of myrislignan in animals and humans. 
Table 3 Stability of myrislignan in mouse plasma samples under various conditions $(n=6)$

\begin{tabular}{|c|c|c|c|}
\hline Storage conditions & Concentration (ng/mL) & Accuracy \pm SD (\%) & RSD (\%) \\
\hline \multirow[t]{3}{*}{ Ambient temperature for $24 \mathrm{~h}$} & 15 & $92.22 \pm 6.02$ & 6.53 \\
\hline & 400 & $99.24 \pm 4.32$ & 4.35 \\
\hline & 800 & $108.98 \pm 3.63$ & 3.33 \\
\hline \multirow[t]{3}{*}{ At $-20^{\circ} \mathrm{C}$ for 60 days } & 15 & $104.21 \pm 7.62$ & 7.31 \\
\hline & 400 & $102.35 \pm 6.54$ & 6.39 \\
\hline & 800 & $110.02 \pm 3.84$ & 3.49 \\
\hline \multirow[t]{3}{*}{ At $4{ }^{\circ} \mathrm{C}$ in the autosampler for $24 \mathrm{~h}$} & 15 & $106.26 \pm 5.43$ & 5.11 \\
\hline & 400 & $108.49 \pm 1.98$ & 1.83 \\
\hline & 800 & $99.63 \pm 7.67$ & 7.70 \\
\hline \multirow[t]{3}{*}{3 Freeze-thaw cycles } & 15 & $93.02 \pm 3.78$ & 4.06 \\
\hline & 400 & $97.85 \pm 5.30$ & 5.42 \\
\hline & 800 & $101.73 \pm 6.87$ & 6.75 \\
\hline
\end{tabular}

\section{Methods}

\section{Reagents}

Standard myrislignan and dehydrodiisoeugenol were provided by Desite Biotechnology Co., Ltd. (Chengdu, China) (batch numbers DST180502-043 and DST180310-055, respectively, purities $>98 \%$ ). Chromatographic grade ACN and FA were purchased from Fisher Chemical (Waltham, MA, USA). Water was purified with a Milli-Q Plus water system (Millipore Corporation, Bedford, MA, USA) before use. All of the other chemicals and reagents were of chromatographic grade.

\section{Instrumentation}

The LC-MS/MS instrument (API 4000) consisted of an LC system with a binary pump (Model SL) and a triplequadrupole mass spectrometer with an ESI interface

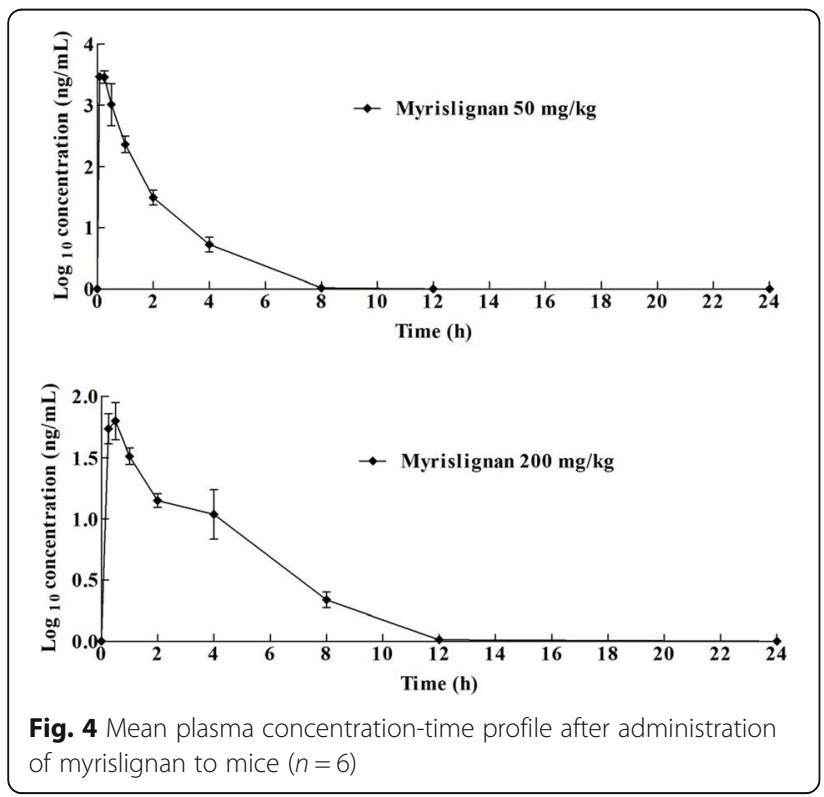

(Agilent Technologies Inc., Santa Clara, CA, USA). The system was controlled using Mass Hunter Analyst software (version 1.6.2, Agilent Technologies Inc.).

\section{LC/MS/MS analysis}

The analytes were separated on an ACE Ultracore Super C18 column $(2.1 \times 50 \mathrm{~mm}, 2.5 \mu \mathrm{m})$ (ACE Chromatography Technology Co., Ltd., UK); mobile phase A $(0.1 \%$ FA in water) and mobile phase $\mathrm{B}(0.1 \% \mathrm{FA}$ in $\mathrm{ACN})$ were used. The mobile phase was delivered at a flow rate of $0.4 \mathrm{~mL} / \mathrm{min}$, and the following gradient profile was used: (1) 0-0.50 min, $45 \% \mathrm{~B}$; (2) 1.30-2.30 min, $95 \% \mathrm{~B}$; (3) $2.31 \mathrm{~min}, 45 \% \mathrm{~B}$; and (4) $3.50 \mathrm{~min}$, stop. The sample was injected at a volume of $10 \mu \mathrm{L}$ at $30{ }^{\circ} \mathrm{C}$.

The Mass spectrometry analysis was performed in positive ion mode. The following MS/MS parameters

Table 4 The pharmacokinetic parameters of myrislignan in mice following oral or intraperitoneal administration $(n=6)$

\begin{tabular}{lll}
\hline Parameters (Units) & \multicolumn{2}{l}{ Mean \pm SD } \\
\cline { 2 - 3 } & Intraperitoneal & Oral \\
\hline $\mathrm{K}_{\mathrm{el}}\left(\mathrm{h}^{-1}\right)$ & $1.19 \pm 0.443$ & $0.366 \pm 0.0789$ \\
$\mathrm{~T}_{1 / 2}(\mathrm{~h})$ & $0.692 \pm 0.386$ & $1.97 \pm 0.426$ \\
$\mathrm{~T}_{\max }(\mathrm{h})$ & $0.167 \pm 0.0915$ & $1.04 \pm 1.45$ \\
$\mathrm{C}_{\max }(\mathrm{ng} / \mathrm{mL})$ & $3870 \pm 1200$ & $105 \pm 72.3$ \\
$\mathrm{Cl}_{-} \mathrm{F}_{\text {obs }}(\mathrm{mL} / \mathrm{hr} / \mathrm{kg})$ & $45,123 \pm 11,936$ & $302,900 \pm 442,668$ \\
$\mathrm{Vz}_{-} \mathrm{F}_{\text {obs }}(\mathrm{mL} / \mathrm{kg})$ & $24,198 \pm 5987$ & $970,149 \pm 199,518$ \\
$\mathrm{AUC}_{0-\mathrm{t}}(\mathrm{h} / \mathrm{ng} / \mathrm{mL})$ & $2050 \pm 532$ & $157 \pm 55.1$ \\
$\mathrm{AUC}_{0-\text { inf }}(\mathrm{h} / \mathrm{hg} / \mathrm{mL})$ & $2060 \pm 536$ & $162 \pm 52.9$ \\
$\mathrm{AUMC}_{\text {last }}(\mathrm{hr}$ (hr*ng/mL) & $1006 \pm 227$ & $457 \pm 240$ \\
$\mathrm{MRT}_{0-\mathrm{t}}(\mathrm{h})$ & $0.457 \pm 0.0499$ & $2.19 \pm 0.841$ \\
$\mathrm{MRT}_{0-\text { inf }}(\mathrm{h})$ & $0.466 \pm 0.0485$ & $2.57 \pm 0.858$ \\
$\mathrm{~F}^{*}=1.97 \%$ & & \\
\hline
\end{tabular}


were used: ion spray voltage, $5 \mathrm{kV}$; source temperature, $500{ }^{\circ} \mathrm{C}$; curtain gas pressure, $20 \mathrm{psi}$; nebulizer gas (GS1) pressure, 55 psi; and auxiliary nitrogen gas (GS2) pressure, 55 psi. The declustering potentials (DPs) for myrislignan and IS were 64 and $70 \mathrm{~V}$, respectively. Data were collected in MRM mode using $[\mathrm{M}+\mathrm{Na}]^{+}$ions for myrislignan and $[\mathrm{M}+\mathrm{H}]^{+}$ions for the IS, with collision energies (CE values) for the transitions of $\mathrm{m} / \mathrm{z} 397.4 \rightarrow 216.1$ and $\mathrm{m} / \mathrm{z} 327.4 \rightarrow 203.3$ of $30 \mathrm{eV}$ and $19 \mathrm{eV}$, respectively. The entrance potential (EP) for both myrislignan and IS was $10 \mathrm{~V}$, and the collision cell exit potentials (CXP) for myrislignan and the IS were 12 and $13 \mathrm{~V}$, respectively.

\section{Preparation of working, calibration and quality control standard solutions}

For the standard stock solution of myrislignan, $100 \mathrm{mg}$ of myrislignan were placed into a $100 \mathrm{~mL}$ brown volumetric flask, after which methanol was added to produce a stock solution of $1000 \mu \mathrm{g} / \mathrm{mL}$ myrislignan. Standard working solutions were prepared from the myrislignan stock solution by dilution with methanol and water (4:1). Calibration standards were prepared by diluting the corresponding standard working solutions with blank mouse plasma to achieve final concentrations of 1.00 , 2.00, 5.00, 10.0, 50.0, 200, 500 and $1000 \mathrm{ng} / \mathrm{mL}$. QC samples with concentrations of $1 \mathrm{ng} / \mathrm{mL}$ (LLOQ), $15 \mathrm{ng} /$ $\mathrm{mL}$ (LQC, low-quality control), $400 \mathrm{ng} / \mathrm{mL}$ (MQC, medium-quality control) and $800 \mathrm{ng} / \mathrm{mL}$ (HQC, highquality control) were prepared in a similar manner.

For the IS solution, $100 \mathrm{mg}$ of IS were placed into a $100 \mathrm{~mL}$ brown volumetric flask, and methanol was added to produce a stock solution of $1000 \mu \mathrm{g} / \mathrm{mL}$ IS. The IS stock solution was further diluted with acetonitrile to prepare the working solution $(50 \mathrm{ng} / \mathrm{mL})$. All of the solutions were stored at $4{ }^{\circ} \mathrm{C}$ and brought to room temperature before use [23].

\section{Sample preparation}

A $20 \mu \mathrm{L}$ aliquot of sample was added to $180 \mu \mathrm{L}$ of ACN containing the IS (IS, $50 \mathrm{ng} / \mathrm{mL}$ ), and the mixture was vortexed for $10 \mathrm{~min}$ and then centrifuged at $3700 \mathrm{rpm}$ for $10 \mathrm{~min}$. Then, $80 \mu \mathrm{L}$ of the supernatant were added to $80 \mu \mathrm{L}$ of water and vortexed for $10 \mathrm{~min}$, after which the solution was filtered through a $0.22 \mu \mathrm{m}$ Millipore filter. A $10 \mu \mathrm{L}$ aliquot of the mixture was injected into the LC-MS/MS system.

\section{Method validation}

The LC-MS/MS method was validated in terms of the selectivity, linearity, matrix effect, LLOQ, recovery, accuracy, precision, stability and dilution integrity.

\section{Selectivity and matrix effects}

Selectivity was evaluated by analysing nine different batches from multiple types of mice to confirm the absence of interfering peaks. The presence of carryover was tested by subjecting a blank sample to chromatographic separation after a myrislignan sample had been analysed to determine whether any similar peaks appeared in the chromatogram of the blank sample [24].

The matrix effect was defined as the response ratios of analyte dissolved in pretreated blank matrix samples spiked with myrislignan at three QC levels with standard solutions of equivalent concentrations that had been directly dried and reconstituted with the same mobile phase [25].

\section{$\angle L O Q$ and linearity}

The LLOQ and the LLOD were calculated based on the ratios of signal to baseline noise $(\mathrm{S} / \mathrm{N})$ of least 10 and 3 , respectively. The calibration curve for myrislignan was linear at concentrations ranging from 1.000 to $1000 \mathrm{ng} /$ $\mathrm{mL}$, and a coefficient of correlation $\left(\mathrm{r}^{2}\right)$ of at least 0.99 was required to meet the criterion. The calibration curve was constructed by plotting the ratio of the peak areas of myrislignan/IS (y) against the nominal concentration of myrislignan $(x)$ in the form of $y=a x+b$, and the least squares method was used for the linear regression analysis [23].

\section{Accuracy and precision}

The precision method was determined as the RSD of replicate measurements, and accuracy was evaluated as the ratio of the calculated and theoretical concentrations, as previously described [25]. The intraday accuracy and precision of the HPLC-MS/MS method were assessed by analysing QC samples at concentrations of $15.0 \mathrm{ng} / \mathrm{mL}, 400 \mathrm{ng} / \mathrm{mL}$ and $800 \mathrm{ng} / \mathrm{mL}$, and the LLOQ concentration was assessed using six replicates per concentration on the same day. Interday accuracy and precision were evaluated by analysing QC solutions at concentrations of $15.0 \mathrm{ng} / \mathrm{mL}, 400 \mathrm{ng} / \mathrm{mL}$, and $800 \mathrm{ng} /$ $\mathrm{mL}$ and the LLOQ concentration with six determinations per concentration over 3 days [26]. According to the ICH [27], the criterion for precision and accuracy was that the RSD should be $\leq 15 \%$ for each concentration except the LLOQ $(\leq 20 \%)$.

\section{Recovery and stability}

The recovery was determined by comparing the analytical results of the extracted QC samples with the pure standards without extraction. Three concentrations of QC samples (15.0 ng/mL, $400 \mathrm{ng} / \mathrm{mL}$ and $800 \mathrm{ng} / \mathrm{mL}$ ) were evaluated with six replicates per concentration to evaluate the efficiency of myrislignan extraction from the biological matrix.

The stability of myrislignan exposed to mouse plasma was investigated by analysing replicates $(n=6)$ of the QC samples at concentrations of $15.0 \mathrm{ng} / \mathrm{mL}, 400 \mathrm{ng} /$ 
$\mathrm{mL}$ and $800 \mathrm{ng} / \mathrm{mL}$ under various sample storage and processing conditions [28]: (1) kept at $25^{\circ} \mathrm{C}$ for $4 \mathrm{~h}$ (ambient stability); (2) stored at $-20^{\circ} \mathrm{C}$ for 60 days (longterm stability); (3) kept in the autosampler for $24 \mathrm{~h}$ at $4{ }^{\circ} \mathrm{C}$ (autosampler stability); and (4) three freeze/thaw cycles $\left(-20^{\circ} \mathrm{C}\right.$ to $25^{\circ} \mathrm{C}$, freeze-thaw stability) [26].

\section{Dilution integrity}

The dilution integrity of myrislignan in plasma was studied to determine whether myrislignan was accurately quantified at concentrations exceeding the maximum value of the calibration curve. Plasma samples $(n=6)$ at concentrations ranging from 4000 to $1000 \mathrm{ng} / \mathrm{mL}$ were diluted ten-fold with blank plasma. The diluted samples were further quantified with respect to the calibration curve. The accuracy and precision of the determination after dilution should be within the acceptable limit (RSD\%, $15 \%$ ).

\section{Pharmacokinetic study in mice}

Thirty-six healthy BALB/c mice of both sexes with body weights (BW values) of $18.00 \pm 2.00 \mathrm{~g}$ were purchased from Beijing Vital River Laboratory Animal Technology Co., Ltd. (animal certification number: male, 11400700331244; female, 11400700331308), and acclimatized to a standard, environmentally controlled animal room (temperature, $25 \pm 2{ }^{\circ} \mathrm{C}$; relative humidity of $50 \%$ and a 12:12-h light/dark cycle) for 1 week before the experiment. Adequate water and food were provided. All of the experimental methods, the animal care and the barn environment of this study strictly complied with the Guide for the Care and Use of Laboratory Animals, Lanzhou Institute of Husbandry and Pharmaceutical Sciences, China. The experiment has been approved by the institutional ethics committee of Lanzhou Institute of Husbandry and Pharmaceutical Sciences, China, and the certificate number was SCXK (Gan) 2019-0010. In addition, all efforts were made to minimize suffering. At the end of the experiment, mice were moved into a carbon dioxide death chamber, anesthetised with sevoflurane, and then humanely killed with carbon dioxide. During the operation, the mice were as gentle as possible to minimize the suffering. The mice were confirmed to be motionless and not breathing, and were confirmed to be dead after two minutes of observation.

Animals were administered myrislignan once, and the dose was based on the live weight. For intraperitoneal injections, myrislignan was dissolved in isotonic saline containing $10 \%$ ethanol and $10 \%$ Cremophor EL at a concentration of $5 \mathrm{mg} / \mathrm{mL}$. For oral administration, myrislignan was suspended in $0.5 \%$ carboxymethyl cellulose and $0.5 \%$ Tween 80 to a final concentration of $20 \mathrm{mg} /$ $\mathrm{mL}$. Mice were randomly divided into two groups $(n=$ 18 animals per group). One group received an oral dose of $200 \mathrm{mg} / \mathrm{kg}$ myrislignan, and blood samples $(80 \mu \mathrm{L})$ were collected int heparinized centrifuge tubes from the orbital sinus venous plexus at $0,0.25,0.5,1,2,4,8,12$ and $24 \mathrm{~h}$ post-dose. Mice in the other group received an intraperitoneal injection of $50 \mathrm{mg} / \mathrm{kg}$ myrislignan, and blood samples $(80 \mu \mathrm{L})$ were collected in heparinized centrifuge tubes from the orbital sinus venous plexus at $0,0.083,0.25,0.5,1,2,4,8,12$ and 24 h post-dose postdose. Each blood sample was centrifuged at $3000 \mathrm{rpm}$ for $10 \mathrm{~min}$, and then a plasma sample was collected and immediately stored in a $-20{ }^{\circ} \mathrm{C}$ freezer until analysis using LC-MS/MS.

The best pharmacokinetic model was confirmed according to the minimum Akaike Information Criterion (AIC) value principle and utilized for data fitting and parameter estimation [29]. Accordingly, the pharmacokinetic parameters were estimated by a noncompartmental model using WinNonlin Professional software, version 8.0 (Pharsight, Mountain View, CA, USA). The $\mathrm{K}_{\mathrm{el}}$,

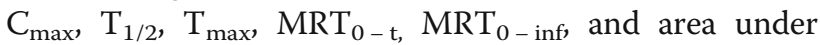
the concentration-time curve from time zero to the last time point $\left(\mathrm{AUC}_{0-\mathrm{t}}\right)$ and to infinity $\left(\mathrm{AUC}_{0-\mathrm{inf}}\right)$ were calculated from the data. The oral bioavailability, F (\%), of myrislignan was evaluated using the following formula [30]:

$$
\mathrm{F}(\%)=\frac{\mathrm{AUC}(\text { p.o. }) / \operatorname{Dose}(\text { p.o. })}{\mathrm{AUC}(\text { i.p. }) / \operatorname{Dose}(\text { i.p. })} \times 100 \%
$$

where $\mathrm{AUC}_{(\text {p.o.) }}$ and $\mathrm{AUC}_{(\text {i.p.) }}$ represent the values for $\mathrm{AUC}_{(0-\mathrm{inf})}$ in the oral and intraperitoneal administration groups, respectively.

The experiment has been approved by the institutional ethics committee of Lanzhou Institute of Husbandry and Pharmaceutical Sciences, China, and the certificate number was SCXK (Gan) 2019-0010. All of the experimental methods, the animal care and the barn environment of this study strictly complied with the Guide for the Care and Use of Laboratory Animals, Lanzhou Institute of Husbandry and Pharmaceutical Sciences, China. The study was carried out in compliance with the ARRIVE guidelines.

\footnotetext{
Abbreviations

$\mathrm{AUC}_{0-\mathrm{t}}$ : Area under the concentration-time curve from time zero to the last time point; $A_{U} C_{0}$-inf: Area under the concentration-time curve from time zero to infinity; BW: Body weight; $C_{\text {max }}$ : Peak plasma concentration; ESI: Electrospray ionization; HPLC-MS/MS: High-performance liquid chromatography-tandem mass spectrometry; IS: Internal standard; LC-MS/ MS: Liquid chromatography coupled with tandem mass spectrometry; LLOD: Lower limit of detection; LLOQ: Lower limit of quantification; MRM: Multiple reaction monitoring; QC: Quality control; RSD: Relative standard deviation; Tmax: Peak time; $\mathrm{T}_{1 / 2}$ : Half-life; F: Bioavailability; HPLC: High-performance liquid chromatography; FA: Formic acid; ACN: Acetonitrile; DP: Declustering potentials; EP: Entrance potential; CXP: Collision cell exit potentials; CE: Collision energy; LQC: Low quality control; MQC: Medium quality control; HQC: High quality control; $r^{2}$ : Coefficient of correlation
} 


\section{Acknowledgements}

Not applicable.

\section{Authors' contributions}

$\mathrm{XZ}$ and BL participated in the animal experiments. BQY, JCS, KL and HS revised the manuscript. JLZ supervised the experiments and wrote the manuscript. JYZ designed the study and critically revised the manuscript. All of the authors read and approved the final manuscript.

\section{Funding}

This study was supported by grants from the Key Project in the National Science \& Technology Pillar Program during the Twelfth Five-year Plan Period (2015BAD11B01) and by the earmarked fund for the China Agriculture Research System (CARS-37). The funding organizations played no role in the design of the study and collection, analysis, and interpretation of data or in the writing the manuscript.

\section{Availability of data and materials}

All of the data generated or analysed during this study are available from the corresponding author on reasonable request.

\section{Declarations}

All of the authors declare the absence of any financial or personal interests that could have inappropriately influenced the current study. The final article has been approved by all of the authors.

\section{Ethics approval and consent to participate}

The study was carried out in compliance with the ARRIVE guidelines. The study, executed by Dr. Jili Zhang and Dr. Jiyu Zhang, was conducted between March and April 2019 at the Lanzhou Institute of Husbandry and Pharmaceutical Sciences of Lanzhou, Gansu Province, China. Thirty-six mice were used in this study. All of the experimental methods, the animal care and the barn environment of this study strictly complied with the Guide for the Care and Use of Laboratory Animals, Lanzhou Institute of Husbandry and Pharmaceutical Sciences, China. In addition, all efforts were made to minimize suffering. Thus, we agreed to conduct the experiment, and the certificate number was SCXK (Gan) 2019-0010.

\section{Consent for publication}

Not applicable.

\section{Competing interests}

The authors declare that they have no competing interests.

\begin{abstract}
Author details
'Intensive Care Unit, The Affiliated Hospital of Medical School, Ningbo University, Zhejiang Province, Ningbo, People's Republic of China. ${ }^{2}$ School of Medicine, Ningbo University, Ningbo, Zhejiang Province, People's Republic of China. ${ }^{3}$ Lanzhou Institute of Husbandry and Pharmaceutical Sciences, Chinese Academy of Agricultural Sciences, Gansu Province, Lanzhou, People's Republic of China. ${ }^{4}$ College of Pharmacy, Jinan University, Guangzhou, Guangdong Province, People's Republic of China. ${ }^{5}$ College of Veterinary Medicine, Northeast Agricultural University, Harbin, Heilongjiang Province, People's Republic of China. 'SChool of Business, Ningbo University, Ningbo, Zhejiang Province, People's Republic of China. ${ }^{7}$ Key Laboratory of Veterinary Pharmaceutical Development, Lanzhou Institute of Husbandry and Pharmaceutical Sciences, Chinese Academy of Agricultural Sciences, 730050 Lanzhou, People's Republic of China.
\end{abstract}

Received: 16 March 2021 Accepted: 5 August 2021

Published online: 16 August 2021

\section{References}

1. Van Gils C, Cox PA. Ethnobotany of nutmeg in the Spice Islands. J Ethnopharmacol. 1994;42:117-24.

2. Olajide OA, Ajayi FF, Ekhelar Al, Awe SO, Makinde JM, Alada AR. Biological effects of Myristica fragrans (nutmeg) extract. Phytother Res. 1999;13:344-5.

3. Narasimhan B, Dhake AS. Antibacterial principles from Myristica fragrans seeds. J Med Food. 2006;9:395-9.
4. Piaru SP, Mahmud R, Majid AMA, Nassar ZDM. Antioxidant and antiangiogenic activities of the essential oils of Myristica fragrans and Morinda citrifolia. Asian Pac J Trop Med. 2012;5:294-8.

5. Lee JW, Choi YH, Yoo MY, Choi SU, Hong KS, Lee BH, et al. Inhibitory effects of the seed extract of Myristicaceae semen on the proliferation of human tumour cell lines (II). Korean J Pharmacogn. 2006;37:206-11.

6. Lima CC, Criddle DN, Coelho-de-Souza AN, Monte FJ, Jaffar M, Leal-Cardoso $J$ H. Relaxant and antispasmodic actions of methyleugenol on guinea-pig isolated ileum. Planta Med. 2000;66:408-11.

7. Janssens J, Laekeman GM, Pieters LA, Totte J, Herman AG, Vlietinck AJ. Nutmeg oil: identification and quantitation of its most active constituents as inhibitors of platelet aggregation. J Ethnopharmacol. 1990;29:179-88.

8. Isogai A, Murakoshi S, Suzuki A, Tamura S. Isolation from nutmeg of growth inhibitory substances to silkworm larvae. Agric Biol Chem. 1973;37:889-95.

9. Cao GY, Xu W, Yang XW, Gonzalez FJ, Li F. New neolignans from the seeds of Myristica fragrans that inhibit nitric oxide production. Food Chem. 2015; 173:231-7.

10. Shin KH, Woo WS. Inhibition and induction of hepatic mixed function oxidase by phenylpropanoids from the seeds of Myristica fragrans. Han'guk Saenghwa Hakhoechi. 1990;23:122-7.

11. Yang XN, Liu XM, Fang JH, Zhu X, Yang XW, Xiao XR, et al. PPARalpha mediates the hepatoprotective effects of nutmeg. J Proteome Res. 2018;17: 1887-97.

12. Jin H, Zhu ZG, Yu PJ, Wang GF, Zhang JY, Li JR, et al. Myrislignan attenuates lipopolysaccharide-induced inflammation reaction in murine macrophage cells through inhibition of NF-kappaB signalling pathway activation. Phytother Res. 2012;26:1320-6.

13. Lu X, Yang L, Chen J, Zhou J, Tang X, Zhu Y, et al. The action and mechanism of myrislignan on A549 cells in vitro and in vivo. J Nat Med. 2017;71:76-85.

14. Miyazawa M, Kasahara H, Kameoka H. Antifungal activities of 8-0-40neolignans from Myristica fragrans. Nat Prod Lett. 1996;8:271-3.

15. Matsumoto A, Matsumoto T, Tokuda H. Lignans from mace as neoplasm inhibitors. Jpn Kokai Tokkyo Koho. 1991;287:4.

16. Nakajima K, Yamazaki T, Kawashima K, Shinho Y, Kurashige T, Nohara T, et al Vascular smooth muscle contraction inhibitors from Myristica. Jpn Kokai Tokkyo Koho. 1999:8:818.

17. Yang XW, Huang $X, M a ~ L, W u ~ Q, X u W$. The intestinal permeability of neolignans from the seeds of Myristica fragrans in the Caco-2 cell monolayer model. Planta Med. 2010;76:1587-91.

18. Wu N, Xu W, Cao GY, Yang YF, Yang XB, Yang XW. The blood-brain barrier permeability of lignans and malabaricones from the seeds of Myristica fragrans in the MDCK-pHaMDR cell monolayer model. Molecules. 2016;21:134.

19. Li F, Yang X. Quantification of myrislignan in rat plasma by solid-phase extraction and reversed-phase high-performance liquid chromatography. Biomed Chromatogr. 2008;22:601-5.

20. Zhu Z, Yang S, Zhao W, Li R, Zhao C. A comparative pharmacokinetic study of myrislignan by UHPLC-MS after oral administration of a monomer and Myristica fragrans extract to rats. J Chromatogr Sci. 2016;54:689-96.

21. US Food and Drug Administration. Guidance for industry: bioanalytical method validation. Rockville: US Department of Health and Human Services, Food and Drug Administration, Center for Drug Evaluation and Research; 2018.

22. Gokbulut C, Yalinkilinc HS, Aksit D, Veneziano V. Comparative pharmacokinetics of levamisole-oxyclozanide combination in sheep and goats following per os administration. Can J Vet Res. 2014;78:316-20.

23. Zhang J, Bai Y, Li B, Zhou X, Si H, Zhang J. Determination and pharmacokinetics study of oxyclozanide suspension in cattle by LC-MS/MS. BMC Vet Res. 2019;15(1):210.

24. Kadi AA, Alrabiah H, Attwa MW, Attia S, Mostafa GAE. Development and validation of HPLC-MS/MS method for the determination of lixivaptan in mouse plasma and its application in a pharmacokinetic study. Biomed Chromatogr. 2017;31:e4007.

25. Liu SJ, Zhou L, Zhang J, Yu BY, Li CY, Liu ZX, et al. Determination of limonin in dog plasma by liquid chromatography-tandem mass spectrometry and its application to a pharmacokinetic study. Biomed Chromatogr. 2013;27: 515-9.

26. Li B, Gong SY, Zhou XZ, Yang YJ, Li JY, Wei XJ, et al. Determination of antibacterial agent tilmicosin in pig plasma by LC/MS/MS and its application to pharmacokinetics. Biomed Chromatogr. 2017;31:e3825. 
27. ICH Harmonised Tripartite Guideline. Validation of analytical procedures: text and methodology Q2 (R1). In: International Conference on Harmonization (ICH) of technical requirements for registration of pharmaceuticals for human. Geneva: IFPMA; 2005. p. 1-13.

28. Chen Q, Li P, Zhang J, Zhu J. Preclinical pharmacokinetic analysis of armillarisin succinate ester in mouse plasma and tissues by LC-MS/MS. Biomed Chromatogr. 2013;27:130-6

29. Klinkenberg D, Tobias TJ, Bouma A, van Leengoed LAMG, Stegeman JA. Simulation study of the mechanisms underlying outbreaks of clinical disease caused by Actinobacillus pleuropneumoniae in finishing pigs. Vet J. 2014;202:99-105.

30. Chen W, Yeo SC, Chuang XF, Lin HS. Determination of pinostilbene in rat plasma by LC-MS/MS: application to a pharmacokinetic study. J Pharm Biomed Anal. 2016;120:316-21.

\section{Publisher's Note}

Springer Nature remains neutral with regard to jurisdictional claims in published maps and institutional affiliations.

- fast, convenient online submission

- thorough peer review by experienced researchers in your field

- rapid publication on acceptance

- support for research data, including large and complex data types

- gold Open Access which fosters wider collaboration and increased citations

- maximum visibility for your research: over $100 \mathrm{M}$ website views per year

At $\mathrm{BMC}$, research is always in progress. 